\title{
Gestational trophoblastic disease with multisistemic complications
}

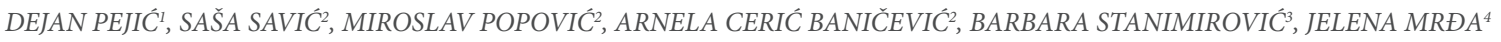 \\ ${ }^{1}$ General Hospital Gradiška, Gradiška \\ ${ }^{2}$ Clinic of Obstetrics and Gynecology, University Hospital, Clinical Centre, Banjaluka \\ ${ }^{3}$ Clinic of Paediatrics, University Hospital, Clinical Center, Banjaluka \\ ${ }^{4}$ Clinic of Internal medicine, University Hospital, Clinical Centre, Banjaluka, Bosnia and Herzegovina
}

Corresponding author:

Dejan Pejić, General Hospital Gradiška,

Mladena Stojanovića 10, 78400 Gradiška, BiH

Phone: + 38751810 659, Fax: + 38751810602

E-mail:dejanpejic80@hotmail.com

\section{ABSTRACT}

Gestational trophoblastic disease (GTD) is a condition of uncertain etiology, comprised of a hydatidiform mole (complete and partial), invasive mole, choriocarcinoma, epithelioid trophoblastic tumour and placental site trophoblastic tumour.

A partial hydatidiform mole develops when dispermy occurs, and the resulting conceptus is triploidy.

A 26-year-old woman (Gravida 2, Para 1 , with one previous vaginal delivery of a normal female infant) was 16 weeks pregnant and was scheduled for emergency surgical treatment. She was diagnosed with a hydatidiform mole and eclampsia in our hospital for further treatment.

Her pre-treatment beta human chorionic gonadotropin ( $\beta$-HCG) level was extremely high at $1,082,900 \mathrm{mIU} / \mathrm{ml}$. The obstetricians considered septic complications from the hydatidiform mole and we decided to perform an emergency Sectio parva. Two weeks after delivery, the serum $\beta$-hCG level was $16,341 \mathrm{mlU} / \mathrm{mL}$ and normalized gradually within two months without any cytotoxic therapy.

Partial mole hydatidosa (PMH), as a milder form of GTD, can go along with malignant complications with fatal consequences.

Key words: gestational trophoblastic disease, eclampsia, chorionic gonadotropin beta subunit.

\section{INTRODUCTION}

Gestational trophoblastic disease (GTD) is a condition of uncertain etiology, comprised of a hydatidiform mole (complete and partial), invasive mole, choriocarcinoma, epithelioid trophoblastic tumour and placental site trophoblastic tumour. (1)

The incidence of a complete hydatidiform mole is approximately 1 in 1,500 pregnancies in the United States. The incidence of a partial hydatidiform mole is approximately 1 in 750 pregnancies.

A complete hydatidiform mole is usually due to an androgenetic diploid conception, in which a haploid sperm fertilizes an egg that lacks female chromosomes. (2)

A partial hydatidiform mole (PHM) develops when dispermy occurs, and the resulting conceptus is triploidy. (1)

\section{CASE REPORT}

In this case report we describe a patient with symptoms of eclampsia induced by molar pregnancy.

A 26-year-old woman (Gravida 2, Para 1, with one previous vaginal delivery of a normal female infant) was 16 weeks pregnant and was scheduled for emergency surgical treatment. She was diagnosed with a hydatidiform mole and eclampsia, and kept in our hospital for further treatment. She had no medical or surgical history, and her vital signs upon admission were $70 / 100 \mathrm{~mm} \mathrm{Hg}$, $88 / \mathrm{min}-18 / \mathrm{min}-36.9^{\circ} \mathrm{C}$.

On admission she had irregular vaginal bleeding, lower abdominal pain, syncopa, headache, excessive vomiting, transvaginal expulsion of grape-like vesicles, an ab-

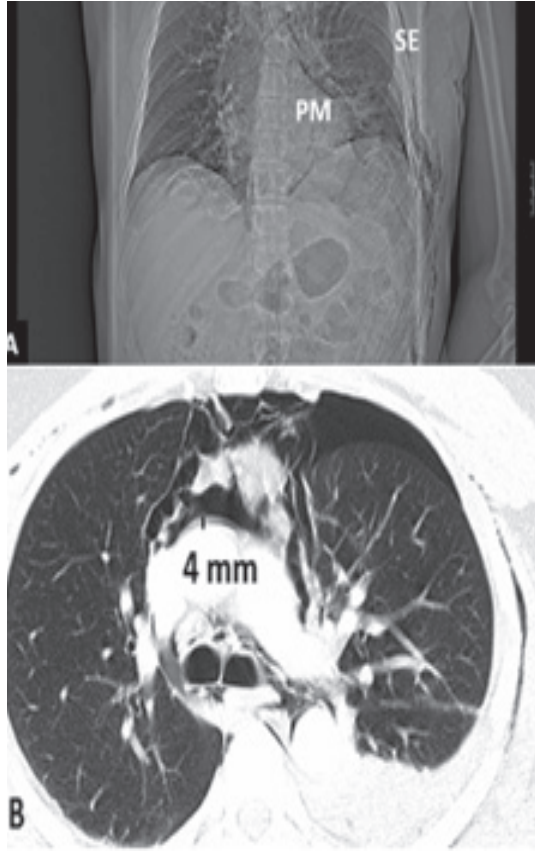

Figure 1. CT scan $(120 \mathrm{kV}, 436 \mathrm{~mA}$, IV contrast) A: pneumomediastinum (PM), left side pneumothorax (PT) and subcutaneous emphysema (SE); B: pneumopericardium of $4 \mathrm{~mm}$.

normally enlarged uterus and features of eclampsia. Her pre-treatment beta human chorionic gonadotropin ( $\beta-\mathrm{HCG}$ ) level was extremely high at 1,082,900 $\mathrm{mIU} / \mathrm{ml}$ (normal: 0.5-2.9 $\mathrm{mIU} / \mathrm{ml}$ ).

Her base line investigation showed $\mathrm{Hb}$ 132g/L, PLT-278x109/L, normal differential count, $\mathrm{ABO} / \mathrm{Rh} \mathrm{B}+\mathrm{ve}$, proteinuria $3+$ dipstick and Thyrotropin (TSH) was 1.88 $\mathrm{uIU} / \mathrm{ml}$ with normal free thyroxine (FT 4). Her blood sugar level, renal and liver function tests were all within normal limits.

An ultrasound examination performed on admission showed a viable fetus with 
normal anatomy and placenta located at the posterior uterine wall, and a second multicystic molar-appearing placenta. The ovaries showed bilateral multilocular cystic masses with a dimension of $70 \times 40 \mathrm{~mm}$.

The magnetic resonance imaging (MRI) of the brain showed hypodense lesions at the gray-white matter junction and diffuse cerebral edema primarily in the parietooccipital lobe, frontal and inferior temporal lobes.

The obstetricians suspected eclampsia and magnesium sulphate and sodium thiopental were administered repeatedly, but they were not effective for controlling the blood pressure and heart rate. The obstetricians considered septic complications from the hydatidiform mole and it was decided that an emergency sectio parva under general anaesthesia would be performed.

On pathological examination, the placenta was $22 \times 16 \times 4 \mathrm{~cm}$, weight $422.5 \mathrm{~g}$. The microscopic findings consisted of partial mole hydatidosa with trophoblastic atypias, mild hyperplasia and spontaneous degeneration areas. The pathology diagnosis was gestational trophoblastic disease - partial mole hydatidosa (PMH).

At the end of the 40 minute operation, the patient was sent to the recovery room in an intubated state. Her estimated blood loss was $200 \mathrm{ml}$ and $500 \mathrm{ml}$ crystalloid was in- fused (figure 1).

In the Intensive Care Unit, and on the first day after the operation, the patient was put on mechanical ventilation and developed right side paralysis, amaurosis, hypoproteinemia $(40 \mathrm{~g} / \mathrm{L})$.

Postoperatively, she received parenteral therapy: antibiotics meropenem and metronidazol antimycotics aciklovir, human albumins, antiepileptics drug levetiracetam, crystalloid and colloids solutions.

Seven days after the operation, subsequent investigations confirmed normal thyroid function tests, normal vision, normal blood pressure, no proteinuria and a normal chest X-ray.

Two weeks after delivery, the serum $\beta$-hCG level was $16,341 \mathrm{mlU} / \mathrm{mL}$ and normalized gradually within two months without any cytotoxic therapy and with no evidence of persistent or metastatic disease. Careful follow-up has so far shown no sign of persistent trophoblastic disease (table 1).

The patient has been transferred to the Institute of Physical Medicine and Rehabilitation "Dr. Miroslav Zotović" for physical therapy.

\section{DISCUSSION}

In our case the patient was presented with partial molar pregnancy with symptoms of eclampsia prior to 20 weeks' gestation.

Ultrasonography made possible a diagnosis of a hydatidiform mole and co-existent fetus in the first trimester. (3)

Partial moles derive from dispermic fertilization of a haploid normal oocyte and produce a triploid set of chromosomes. Complete and partial moles have distinct fetal and maternal complications. In the combination of a partial hydatidiform mole, the fetus is almost always triploid and the indication for a termination of pregnancy is evident. (4)

Eclampsia is associated with blood pressure $\geq 160 / 110 \mathrm{~mm} \mathrm{Hg}$, proteinuria $\geq 2+$ dipstick, persistent headache or other cerebral or visual disturbance, elevated serum transaminase levels, platelets $<100000 / \mu \mathrm{L}$, persistent epigastric pain and seizures that cannot be attributed to other causes. (5)

\section{CONCLUSION}

The occurrence of eclampsia before 20 weeks' gestation is rather rare and is often combined with the occurrence of GTD. It is important to recognize the symptoms of both conditions promptly and to then treat them adequately.

Table 1. Evolution of beta-HCG levels.

\begin{tabular}{ll}
\hline Evolution of beta-HCG levels. & \\
\hline Date & beta-HCG $(\mathrm{UI} / \mathrm{ml})$ \\
\hline 18.02 .2015 & 1082235 \\
\hline 19.02 .2015 & 455259 \\
\hline 20.02 .2015 & 210129 \\
\hline 04.03 .2015 & 16341 \\
\hline 15.03 .2015 & 5324 \\
\hline 01.04 .2015 & 300 \\
\hline 18.04 .2015 & 2 \\
\hline
\end{tabular}

Beta-HCG: beta human chorionic gonadotropin

\section{REFERENCES}

1. Abeloff M, Armitage J, Niederhuber J. Abeloff's clinical oncology. Philadelphia . Churchill Livingstone Elsevier. 2008

2. Allen SD, Lim AK, Seckl MJ, Blunt DM, Mitchell AW. Radiology of gestational trophoblastic neoplasia. Clinical Radiology. 2006;61(4):301-313. [PubMed]

3. Montes-de-Oca-Valero F, Macara L, Shaker A. Twin pregnancy with a complete mole and co-existing fetus following in vitro fertilization. Hum Reprod. 1999;14:2905-2907. [PubMed]/

4. Vaisbuch E, Ben-Arie A, Dgani R, Perlman S, Sokolovsky N, Hagay Z. Twin pregnancy consisting of a complete hydatidiform mole and co-existent fetus: report of two cases and review of literature. Gynecol Oncol. 2005;98:19-23. [PubMed]

5. Cunningham G, Leveno C, Bloom S, Hauth J et al. Williams Obstetrics. Parkland. McGraw - Hill Professional Publishing. 2010. 